\title{
Luminescence properties of Sn-containing microcrystals in CsBr:Sn crystal
}

\author{
Savchyn P.V. ${ }^{1}$, Myagkota S.V. ${ }^{2}$, Stryganyuk G.B. ${ }^{3}$, Demkiv T.M. ${ }^{1}$, \\ Datsjuk J.R. ${ }^{1}$, Vus R.B. ${ }^{2}$, Demkiv L.S. ${ }^{4}$ and Voloshinovskii A.S. ${ }^{1}$ ', \\ ${ }^{1}$ Physics Department, Ivan Franko National University of Lviv, \\ 8 Kyrylo and Mefodiy St., 79005 Lviv, Ukraine, savchynp@gmail.com \\ ${ }^{2}$ Lviv State Agrarian University, 1 V. Velykyi St., 80381 Dublyany, Ukraine \\ ${ }^{3}$ Institute for Materials, SRC “Carat”, 202 Stryiska St., 79031 Lviv, Ukraine \\ ${ }^{4}$ Electronics Department, Ivan Franko National University of Lviv, \\ 50 Dragomanov St., 79005 Lviv, Ukraine
}

Received: 17.07 .2008

\begin{abstract}
Formation of $\mathrm{CsSnBr}_{3}$ microcrystals in $\mathrm{CsBr}: \mathrm{Sn}(1 \mathrm{~mol} . \%)$ crystals is revealed after the long-term annealing $\left(\mathrm{t}=100 \mathrm{~h}, \mathrm{~T}=200^{\circ} \mathrm{C}\right)$. Luminescent-kinetic parameters of CsBr:Sn (1 mol.\%) crystals are measured using the excitation with synchrotron radiation. The process of energy transfer from the host to the aggregates is discussed.
\end{abstract}

Keywords: $\mathrm{CsSnBr}_{3}$ microcrystals, luminescence, energy transfer

PACS: 71.35.-y, 71.55.-i, 78.55.-m, 78.55.Fv

UDC: 535.37

\section{Introduction}

Studies for luminescent-kinetic parameters of semiconducting nano- and microcrystals embedded in different insulator matrices represent one of possible ways for searching the materials of different functional use [1]. The appropriate example of those materials is nano- and microcrystals based on mercury-like ions $\left(\mathrm{Pb}^{2+}, \mathrm{Sn}^{2+}, \mathrm{Bi}^{3+}\right.$ and $\left.\mathrm{Sb}^{3+}\right)$, which are promising for applications as fast scintillators [2] and active media of thin-film solid state lasers [3].

A luminescence in the red and infrared ranges of the optical spectrum and unusually high conductivity as for ionic semiconductors $\left(10^{-3}(\mathrm{ohm} \mathrm{cm})^{-1}\right.$ in the order of magnitude) are typical to single $\mathrm{CsSnBr}_{3}$ crystals. However, any applications of $\mathrm{CsSnBr}_{3}$ crystal are hindered by their hydration and oxidation in air. So embedding of $\mathrm{CsSnBr}_{3}$ microcrystals in the $\mathrm{CsBr}$ matrix seems to offer one of the possible solutions for this problem.

The doping of alkali halide crystals with the mercury-like ions leads to creation of uncompensated charges. Therefore the cation vacancies appear in the crystal volume, which compensate the charges. Further on, they form single $\mathrm{Sn}^{2+}-\mathrm{v}_{\mathrm{c}}{ }^{-}$centres with the mercury-like ions, capable of aggregating into micro- or nanophases embedded in the alkali halide host. Investigations of the aggregation processes of single $\mathrm{Sn}^{2+}-\mathrm{v}_{\mathrm{c}}{ }^{-}$centres in 
the $\mathrm{CsBr}$ :Sn crystals using the X-ray and optical spectroscopic techniques have revealed formation of $\mathrm{Cs}_{4} \mathrm{SnBr}_{6}$ and $\mathrm{CsSnBr}_{3}$ microcrystals embedded in the $\mathrm{CsBr}$ matrix [4]. Cathodoluminescence properties of $\mathrm{Cs}_{4} \mathrm{SnBr}_{6}$ and $\mathrm{CsSnBr}_{3}$ microcrystals and their bulk analogues have been found to be identical.

Aiming to elucidate the mechanisms for migration and transformation of highenergy electronic excitations in $\mathrm{CsBr}$ crystals that contain $\mathrm{CsSnBr}_{3}$ microcrystals, in this work we study the luminescent-kinetic properties of $\mathrm{CsBr}$ :Sn crystals at low temperatures $(\mathrm{T}=10 \mathrm{~K})$ and in a wide $(4-16 \mathrm{eV})$ energy range, using the excitation with the synchrotron radiation.

\section{Experimental}

CsBr:Sn crystals ( 1 mol.\% in the melt) were grown with the Bridgman-Stockbarger technique. A long-term $(\mathrm{t}=100 \mathrm{~h})$ annealing $\left(\mathrm{T}=200{ }^{\circ} \mathrm{C}\right)$ of $\mathrm{CsBr}$ :Sn crystal was performed subsequently in order to promote thermally activated migration of ions resulted in the formation of $\mathrm{CsSnBr}_{3}$ microphase embedded in the $\mathrm{CsBr}$ matrix.

Measurements of the emission and luminescence excitation spectra and the decay kinetics were performed under the excitation with synchrotron radiation from DORIS storage ring (DESY, Hamburg), using the facility of SUPERLUMI station at HASYLAB [6]. A cryostat with flowing helium was used to carry out low-temperature $(T=10 \mathrm{~K})$ measurements. The emission spectra were studied within the range of 300-1100 nm with the spectral resolution of $1 \mathrm{~nm}$, using Action Research Corporation (ARC) "Spectra Pro 308" $30 \mathrm{~cm}$ monochromator-spectrograph equipped with the Princeton Instruments CCD detector and HAMAMATSU R6358P photomultiplier (PMT). The excitation spectra were scanned with the resolution of $3.2 \AA$ within $3.7-15 \mathrm{eV}$ by means of primary $2 \mathrm{~m}$ monochromator in $15^{\circ}$ McPearson mounting and ARC monochromator as a secondary one. The luminescence decay kinetics was studied in the range of $200 \mathrm{~ns}$ using time-correlated single-photon counting technique.

\section{Experimental results and discussion}

The luminescence spectra of $\mathrm{CsBr}: \mathrm{Sn}$ crystals excited in the transparency region $\left(\lambda_{\text {exc }}=195 \mathrm{~nm}\right)$ and the fundamental absorption region $\left(\lambda_{\text {exc }}=96 \mathrm{~nm}\right)$ of $\mathrm{CsBr}$ matrix are shown in Fig. 1. The maxima of the main emission bands of CsBr:Sn crystal are observed at $350,485,605,730$ and $1000 \mathrm{~nm}$.

The spectral position of the band peaked at $350 \mathrm{~nm}$ is identical to that of the emission band characteristic of the triplet self-trapped exciton (STE) of CsBr matrix [7]. Efficient excitation of this luminescence band in the regions of excitonic and band-toband absorption of $\mathrm{CsBr}$ matrix confirms that this emission may be really attributed to the triplet STE of CsBr matrix (see Fig. 2a).

The luminescence band with the maximum at $485 \mathrm{~nm}$ is efficiently excited on the long-wave side of the fundamental absorption region of $\mathrm{CsBr}$ matrix. The structure of the 


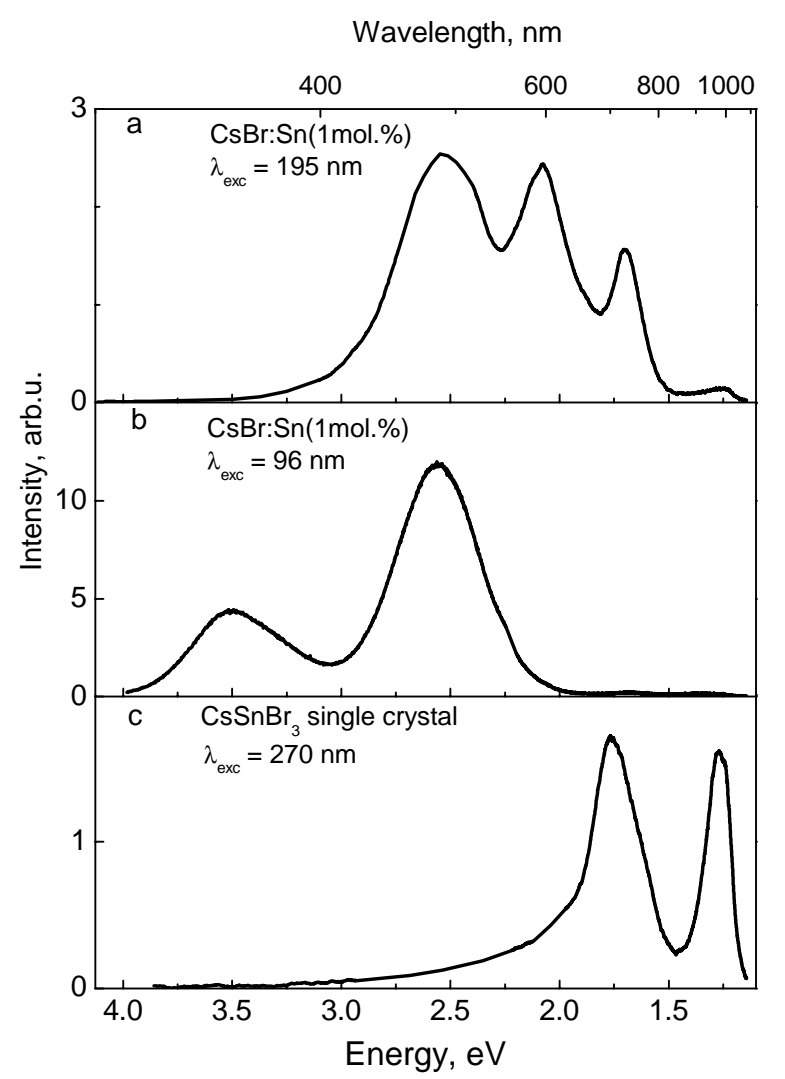

Fig. 1. Emission spectra for CsBr:Sn (1 mol.\%) crystal at $\lambda_{\text {exc }}=195 \mathrm{~nm}$ (a), $\lambda_{\text {exc }}=96 \mathrm{~nm}$ (b) and for $\mathrm{CsSnBr}_{3}$ single crystal at $\lambda_{\mathrm{exc}}=270 \mathrm{~nm}$ (c) measured at $\mathrm{T}=10 \mathrm{~K}$. excitation spectrum of this luminescence at the band-to-band transitions in $\mathrm{CsBr}$ matrix is similar to the excitation spectrum of the STE emission (see Fig. $2 \mathrm{~b}$ and $2 \mathrm{a}$, respectively). Such a structure of the excitation spectrum in the region of generation of electron-hole pairs is typical for the excitation spectrum of near-activator exciton luminescence. For example, a similar structure of the excitation spectrum has been detected for the near-activator exciton in CsBr:Tl crystal [8].

The excitation spectrum of the luminescence band peaked at $605 \mathrm{~nm}$ reveals a structure characteristic for the emission of single mercury-like centres and contains the bands with the maxima located near 300, 275 and $245 \mathrm{~nm}$ (see Fig. 2c). This fact has allowed us to compare these bands with the intra-centric transitions in $\mathrm{Sn}^{2+}$ ion [9] and indicate them as $\mathrm{A}, \mathrm{B}$ and $\mathrm{C}$ bands, respectively. As a result, the band peaked at $605 \mathrm{~nm}$ can be ascribed to the luminescence of single $\mathrm{Sn}^{2+}-\mathrm{v}_{\mathrm{c}}{ }^{-}$centres in the $\mathrm{CsBr}$ matrix.

Concerning their spectral positions, the luminescence bands with the maxima at 730 and $1000 \mathrm{~nm}$ are similar to the intrinsic luminescence bands of single $\mathrm{CsSnBr}_{3}$ crystal located at 705 and $980 \mathrm{~nm}$, respectively (Fig. 1c). According to the works [10, 11], the luminescence band peaked at $730 \mathrm{~nm}$ can be ascribed to the STE emission of $\mathrm{CsSnBr}_{3}$. Then the band around $1000 \mathrm{~nm}$ corresponds to the radiative transition of electron from the $5 \mathrm{~s} 5 \mathrm{p} \mathrm{Sn}^{2+}$ state at the bottom of the conduction band to the conduction sub-band placed lower and created by the $4 \mathrm{~d}$ states of $\mathrm{Br}^{-}$ion .

Similarity of the luminescent characteristics of $\mathrm{CsBr}: \mathrm{Sn}$ and $\mathrm{CsSnBr}_{3}$ in the 700$1000 \mathrm{~nm}$ spectral region points out to the formation of $\mathrm{CsSnBr}_{3}$ phase in $\mathrm{CsBr}: \mathrm{Sn}$ crystal, thus confirming our earlier conclusion about the formation of microphase based upon cathodoluminescence and scanning electron microscopy data [4]. The microphotographs of freshly cleaved surface of $\mathrm{CsBr}: \mathrm{Sn}(1 \mathrm{~mol} \%)$ obtained with the scanning electron microscopy reveals that the average radius of the aggregates is $R \approx 5 \mu \mathrm{m}$ (see Fig. 3). 


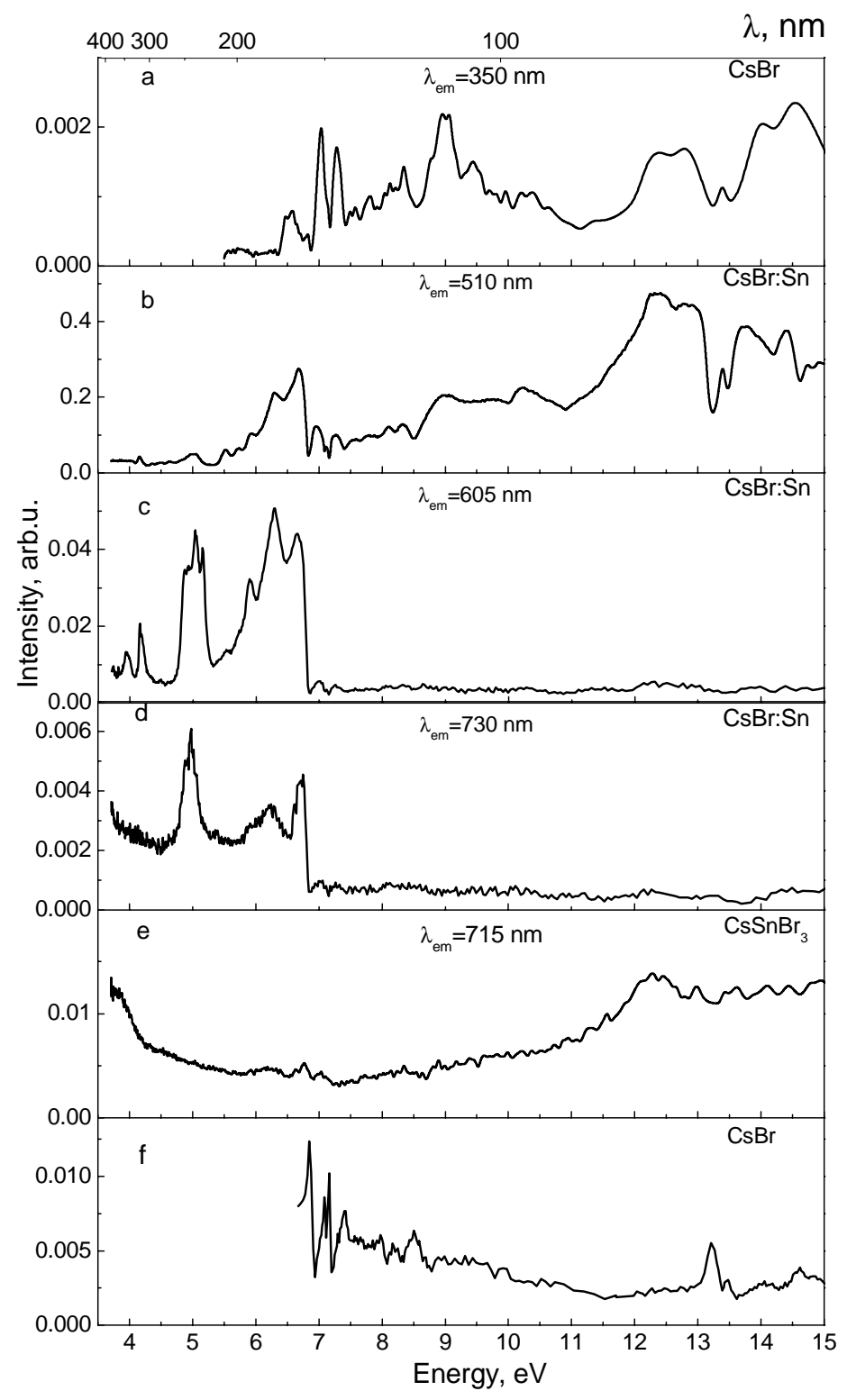

Fig. 2. Excitation spectra for CsBr crystal at $\lambda_{\text {em }}=350 \mathrm{~nm}$ (a), CsBr:Sn (1 mol.\%) crystal at $\lambda_{\mathrm{em}}=510 \mathrm{~nm}$ (b), $605 \mathrm{~nm}$ (c) and $730 \mathrm{~nm}$ (d), $\mathrm{CsSnBr}_{3}$ crystal at $\lambda_{\text {em }}=715 \mathrm{~nm}$ (e), and reflection spectrum for CsBr crystal (f). The temperature is $\mathrm{T}=10 \mathrm{~K}$.

In order to estimate a possibility of quantum confinement effect in $\mathrm{CsSnBr}_{3}$ aggregates, we suggest the following considerations. Basing on the STE character of the emission and the ionic type of the chemical bond in $\mathrm{CsSnBr}_{3}$ crystal, one can state that the excitonic radius $R_{e x}$ of $\mathrm{CsSnBr}_{3}$ crystal does not exceed half the crystal lattice constant for the cubic modification of the structure $(a=5.804 \AA)$ [13]. In other words, we have $R_{\mathrm{ex}}<2.9 \AA$, since the exciton is localized at $\mathrm{Sn}^{2+}$ ion [10]. According to the study [12], the quantum confinement effect is not observed if the average radius of microcrystal 
is $R>10 R_{\text {ex }}$. Therefore, the $R$ parameter should not exceed $29 \AA$ in order that the quantum confinement effect could appear. The radius of the $\mathrm{CsSnBr}_{3}$ phase $\left(50 \times 10^{3} \AA\right)$ is significantly greater than the radius of the microcrystal needed to observe the quantum confinement effect. The data associated with the luminescence spectra confirm this conclusion because the characteristic blue shift of the luminescence bands in the $700-1000 \mathrm{~nm}$ region of $\mathrm{CsSnBr}_{3}$ microcrystals relatively to ones of $\mathrm{CsSnBr}_{3}$ single crystal is not observed.

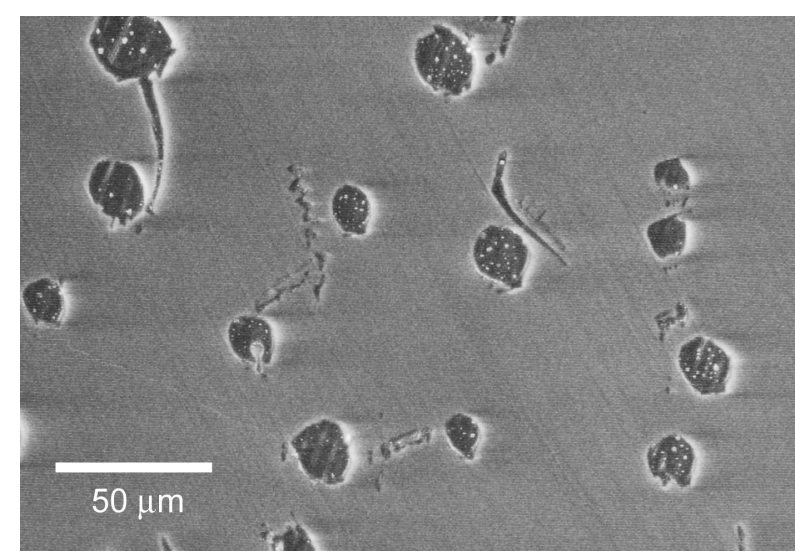

Fig. 3. Microphotographs of freshly cleaved surface of $\mathrm{CsBr}: \mathrm{Sn}$ (1 mol.\%) crystal.

At the same time, a long-wave shift of these bands can be clearly seen (see Fig. 1a and Fig. 1c). The factor that could cause this shift is hydrostatic pressure that affects the microcrystals in the $\mathrm{CsBr}$ matrix. Since $\mathrm{Sn}^{2+}$ and $\mathrm{Pb}^{2+}$ ions are isoelectronic, we suppose that the mechanisms for formation of $\mathrm{CsSnBr}_{3}$ microcrystals and isostructural $\mathrm{CsPbBr}_{3}$ nanocrystals in the $\mathrm{CsBr}$ matrix are analogous [14]. Then the ribs of the elementary cell of $\mathrm{CsSnBr}_{3}$ crystal along $\boldsymbol{a}$ and $\boldsymbol{b}$ directions are parallel to the elementary cell diagonals of $\mathrm{CsBr}$ (see Fig. 4). The crystal lattice parameter of $\mathrm{CsBr}$ is equal to $a=4.29 \AA$ [15] and, as mentioned above, the same parameter for the cubic structure of $\mathrm{CsSnBr}_{3}$ is $a=5.804 \AA$. Thus, one can state that the crystal lattice parameters along the $\boldsymbol{a}$ and $\boldsymbol{b}$ directions are expanded up to $6.07 \AA$, whereas the parameter along the $c$ direction is compressed down to 4.29 A. These structural changes can indeed result in a long-wave shift of the maximum of STE emission band for the $\mathrm{CsSnBr}_{3}$ microcrystal. Besides, the $\mathrm{CsSnBr}_{3}$ microcrystals are also under influence of the $\mathrm{CsBr}$ matrix, due to a difference between the thermal expansion coefficients of $\mathrm{CsBr}$ host and $\mathrm{CsSnBr}_{3}$ microcrystals.

From the analysis of structure of the excitation spectra for micro- and single $\mathrm{CsSnBr}_{3}$ crystals (see Fig. 2c, d and e, respectively) it follows that the luminescence of microcrystals is efficiently excited when the energy of the exciting quanta lies in the transparency region of $\mathrm{CsBr}$ matrix $(E<6.7 \mathrm{eV})$. The boundary between the transparency and absorption regions of the $\mathrm{CsBr}$ matrix is clearly seen from the position of the reflection peak of free exciton in the reflectance spectrum of $\mathrm{CsBr}$ (see Fig. 2f).

Ukr. J. Phys. Opt. 2008, V9, №4 

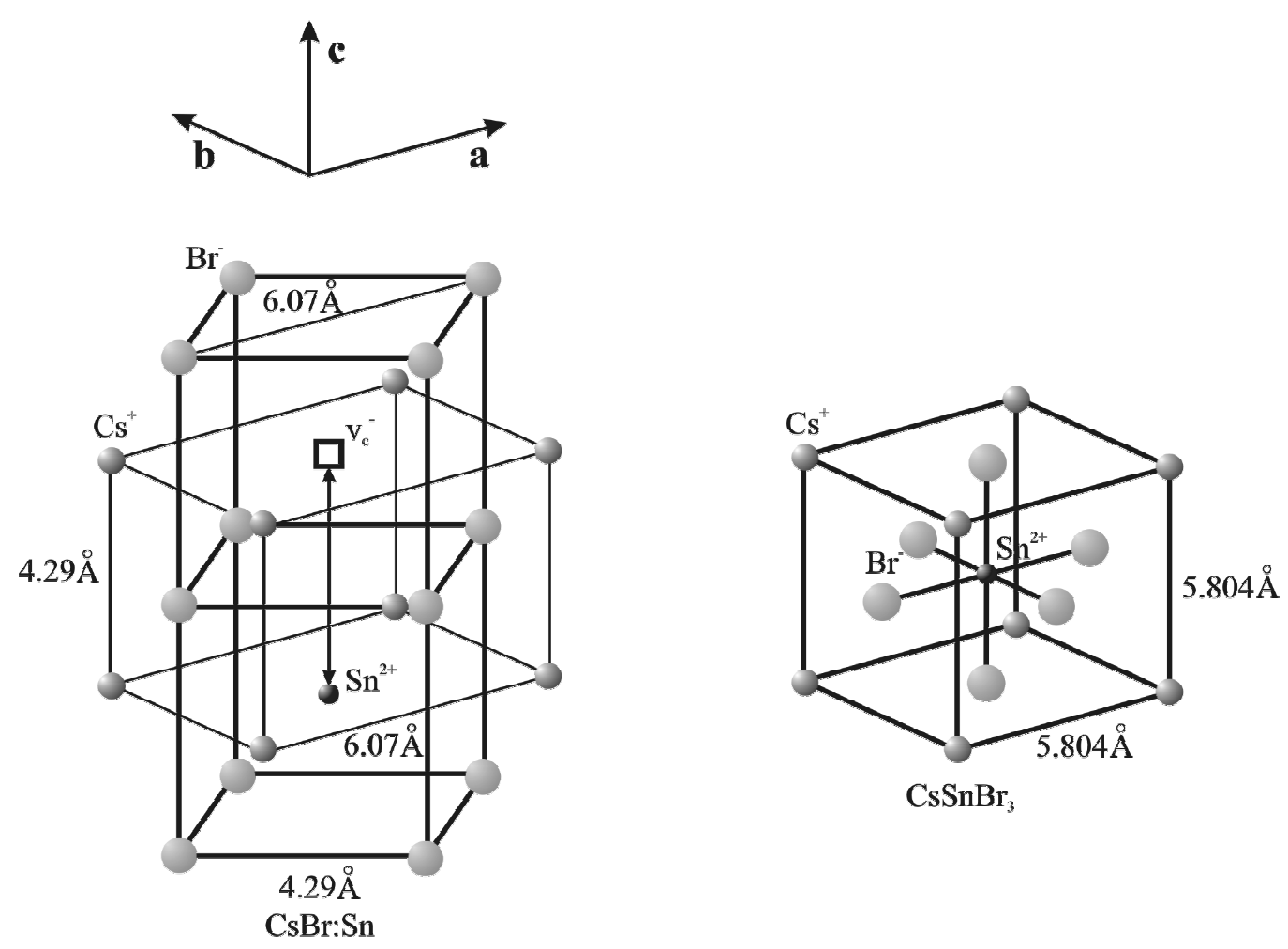

Fig. 4. Schematic representation of crystal lattice structure for $\mathrm{CsBr}: \mathrm{Sn}$ and $\mathrm{CsSnBr}_{3}$ crystals.

The structure of the excitation spectrum of the emission band peaked at $730 \mathrm{~nm}$ for $\mathrm{CsSnBr}_{3}$ microcrystals is similar to the structure typical for mercury-like single $\mathrm{Sn}^{2+}-\mathrm{v}_{\mathrm{c}}{ }^{-}$ centres and near-activator excitons in the transparency region of $\mathrm{CsBr}$ matrix. This points to the fact that the luminescence of single $\mathrm{Sn}^{2+}-\mathrm{v}_{\mathrm{c}}{ }^{-}$centres and near-activator excitons is reabsorbed by $\mathrm{CsSnBr}_{3}$ microcrystals.

The excitation of $\mathrm{CsBr}: \mathrm{Sn}$ crystals in the spectral region of absorption of single $\mathrm{Sn}^{2+}-\mathrm{v}_{\mathrm{c}}{ }^{-}$centres and near-activator excitons leads to domination of 'slow' components in the decay kinetics of the emission band with the maximum at $715 \mathrm{~nm}$, due to efficient re-absorption of their luminescence by $\mathrm{CsSnBr}_{3}$ microcrystals. In the case of microcrystals, the decay kinetics curve is characterized with the decay time constants $\tau_{\mathrm{f}}=5.4 \mathrm{~ns}$ for the 'fast' component and $\tau_{\mathrm{s}}=1.5 \mu$ s for the 'slow' one, while for the single crystal these constants are $\tau_{\mathrm{f}}=3.4 \mathrm{~ns}$ and $\tau_{\mathrm{s}}=0.43 \mu \mathrm{s}$, respectively.

The luminescence excitation efficiency for $\mathrm{CsSnBr}_{3}$ microcrystals in the case of excitation of $\mathrm{CsBr}: \mathrm{Sn}$ crystal in the region of band-to-band transitions is significantly lower than that typical for the case of excitation in the matrix transparency region. This implies that the relaxed electrons and holes do not participate in the energy transfer from the host to microcrystals. 


\section{Conclusion}

Let us finally summarize in brief the major results derived in the present study: the long-term annealing $\left(\mathrm{t}=100 \mathrm{~h}, \mathrm{~T}=200{ }^{\circ} \mathrm{C}\right)$ of $\mathrm{CsBr}$ :Sn $(1 \mathrm{~mol} . \%)$ crystals leads to aggregation of $\mathrm{Sn}^{2+}-\mathrm{v}_{\mathrm{c}}{ }^{-}$single centres, with the formation of $\mathrm{CsSnBr}_{3}$ microcrystals; the luminescence excitation in the $\mathrm{CsSnBr}_{3}$ microcrystals occurs as a result of direct excitation by the light quanta and further re-absorption of the luminescence quanta by single $\mathrm{Sn}^{2+}-\mathrm{v}_{\mathrm{c}}{ }^{-}$centres and near-activator excitons. This re-absorption gives rise to domination of the slow decay component in the decay kinetics peculiar for $\mathrm{CsSnBr}_{3}$ microcrystals;

none energy transfer from the matrix to microcrystals is found upon the band-to-band excitation of CsBr:Sn crystal.

\section{References}

1. Nikl M, Polak K, Nitsch K, Pazzi G P, Fabeni P and Gurioli M, 1995. Optical properties of the $\mathrm{Pb}^{2+}$-based aggregated phase in a $\mathrm{CsCl}$ host crystal: Quantum-confinement effects. Phys. Rev. B 51: 5192-5199.

2. Myagkota S V, 1999. X-ray luminescence spectra of $\mathrm{Pb}^{2+}$ aggregates in $\mathrm{CsX}(\mathrm{X}=\mathrm{Cl}$, Br, I) crystals. Opt. Spektr. 87: 290-294.

3. Kondo S, Kakuchi M, Masaki A and Saito T J, 2003. Strongly Enhanced FreeExciton Luminescence in Microcrystalline $\mathrm{CsPbBr}_{3}$ Films. J. Phys. Soc. Jap. 72: 1789-1791.

4. Savchyn P V, Myagkota S V, Voloshinovskii A S, Demkiv T M and Datsjuk J R, 2007. Luminescent properties of Sn-based microcrystals embedded in $\mathrm{CsBr}$ matrix. Rad. Meas. 42: 697-700.

5. Voloshinovskii A, Myagkota S, Demkiv T, Datsjuk J and Demkiv L. Luminescent material. Declaration patent of Ukraine on the useful model. MPK G01T1/28, No u 2007 01472, approved 12.06.2007. Bulletin No 13.

6. Zimmerer G, 1991. Status report on luminescence investigations with synchrotron radiation at HASYLAB. Nucl. Instr. Meth. Phys. Res. A 308: 178-186.

7. Williams RT and Song KS, 1990. The self-trapped exciton. J. Phys. Chem. Solids. 51: 679-716.

8. Voloshinovskii A, Zazubovich S, Stryganyuk G and Pashuk I, 2005. Luminescence of CsBr:Tl crystals under synchrotron excitation. J. Lumin. 111: 9-15.

9. Jacobs PWM, 1991. Alkali halide crystals containing impurity ions with the $\mathrm{ns}^{2}$ ground-state electronic configuration. J. Phys. Chem. Solids. 52: 35-67.

10. Voloshinovskii A S, Mikhailik V B, Myagkota S V and Pidzyrailo M S, 1992. Electronic states and luminescence properties of $\mathrm{CsSnBr}_{3}$ crystal. Opt. Spektr. 72: 486488.

11. Clark S, Flint C and Donaldson J, 1981. Luminescence and electrical conductivity of $\mathrm{CsSnBr}_{3}$, and related phases. J. Phys. Chem. 42: 133-135. 
12. Ekimov A I, Efros Al L and Onushenko A A, 1985. Quantum Size Effect in Semiconductor Microcrystals. Solid State Commun. 56: 921-924.

13. Zheng Jin-Cheng, Huan CHA, Wee A T S and Kuok M H, 1999. Electronic properties of $\mathrm{CsSnBr}_{3}$ : studies by experiment and theory. Surf. and Interf. Anal. 28: $81-83$.

14. Aceves R, Babin V, Flores MB, Fabeni P, Maaroos A, Nikl M, Nitsch K, Pazzi G P, Salas R P, Sildos I, Zazubovich N and Zazubovich S J, 2001. Spectroscopy of $\mathrm{CsPbBr}_{3}$ quantum dots in $\mathrm{CsBr}: \mathrm{Pb}$ crystals. J. Lumin. 93: 27-41.

15. Narai-Sabo I. Inorganic chemistry. Budapest. Acad. Sci. Hungary (1969). 